\title{
Todes-Anzeige.
}

Mit grossem Bedauern theile ich mit, dass in der Nacht vom 24. bis 25 . Februar unser lieber Oberst Emile Gantior in Genf durch einen Herzschlag seiner Familie und der Wissenschaft entrissen wurde. Am 18. April ${ }^{\circ} 822$ zu Genf geboren und durch seinen Oheim, den hochverdienten Alfred Gautier, schon frühe in den Vorhof der Astronomie eingeführt, hatte sich Emile Gautier in Genf und Paris mit den exacten Wissenschaften vertraut gemacht, sich an letzterem Orte auch die einem Astronomen nothwendigen Fertigkeiten im Beobachten und Rechnen erworben, ja längere Zeit unter Leitung von Leverrier an den ausgedehnten Rechnungen mitgearbeitet, welche schliesslich zur Entdeckung Neptuns futhrten. Nach etwa dreijährigem Aufenthalte in Paris nach Genf zurückgekehrt, arbeitete er daselbst als Dissertation seinen • Essai sur la théorie des perturbations des Comètes, Genève 1847c und mehrere kleinere Mittheilungen für die Astr. Nachr. aus, liess sich dann aber bald durch General Dufour, unter dessen Leitung er sich schon früher ein Officiers-Patent im Genie-Corps erworben hatte, dazu bestimmen, einen grossen Theil seiner Zeit zu Gunsten der gewählten Waffe zu verwenden, betheiligte sich namentlich in den fünfziger Jahren bei den nach Thun einberufenen Schulen in ausgezeichneter Weise an der Instruction der Genieofficiere, und erwies sich auch im Felde sowohl im Jahre 1856 als dann wieder, nachdem er bereits zum Obersten avancirt war, $1870 / 7 \mathrm{x}$ als ein äusserst tüchtiger Officier. Dass Gautier übrigens über diesen militärischen Beschäftigungen seiner Jugendliebe nicht untreu wurde, beweist nicht nur die Reise, welche er 1860 zur Beobachtung der totalen Sonnenfinsterniss nach Spanien unternahm, sondern es bezeugen dies auch manche bemerkenswerthe, namentlich die Sonnen-Physik betreffende Artikel, welche er den in Genf erscheinenden $A$ rchives des sciences physiques et naturelles einverleibte, und es ist so auch ganz begreiflich, dass ihn die Behörden nach dem 1882 erfolgten Tode von Plantamour ersuchten, die Direction der Sternwarte wenigstens interimistisch zu übernehmen, während Prof. Cellérier die Vorlesungen übertragen wurden. Er folgte dieser Einladung, im Gefuhle, dass er während langer Jahre der praktischen Astronomie entfremdet worden sei, nur mit grossen Bedenken, lebte sich aber bald vollständig in seine neue Stellung ein, erwarb sich namentlich durch die Weise, wie er den auf der Genfer Sternwarte so umfangreichen Chronometerdienst leitete, volle Anerkennung, und hatte sodann noch die grosse Freude, nachdem sein Sohn Raoul Gautier die durch den 1889 erfolgten Tod von Cellérier frei gewordene Professur der Astronomie erhalten hatte, diesem auch die Sternwarte in bestem Stande übergeben zu können. Nachdem Emile Gautier, anscheinend noch bei ungeändertem Wohlsein, im Sommer 1890 in Neuenburg einer Sitzung der Schweizerischen geodätischen Com. mission, in welche er nach dem Tode Plantamour's gewählt worden war, beigewolınt hatte, machte in Herbst sein schon vor Jahren begonnenes Herzübel in Folge einer Erkältung höchst bedenkliche Fortschritte, bis dann plötzlich die oben gemeldete Katastrophe seinen I,eiden ein Ende machte.

Zürich I89 I Febr. 28.

Rud. Wolf.

\section{Entdeckung und Beobachtung eines neuen Planeten (307) ${ }^{*}$ )}

auf der Sternwarte des Collegio Romano in Rom.

Studiando il cielo colla Carta No. I I del defunto Peters mi sono ieri sera alle $11^{\text {h }} 17^{\mathrm{m}}$ di Roma imbattuto in un pianeta che deve essere o nuovo (307) o uno dei perduti. La grandezza stimai essere fra ro.8 e r r.0. Ecco il luogo:

$$
\begin{aligned}
& 189 \text { I marzo I } 12^{\mathrm{h}} 5^{\mathrm{m}} 3^{6^{\mathrm{s}}} \text { t. m. Roma } \Delta \alpha=+\mathrm{I}^{\mathrm{m}} 12^{\mathrm{s}} 20 \quad \Delta \delta=+9^{\prime} 17^{\prime \prime} 4 \text { Confr. } 4.4
\end{aligned}
$$

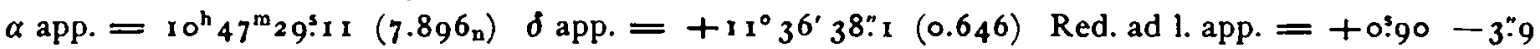

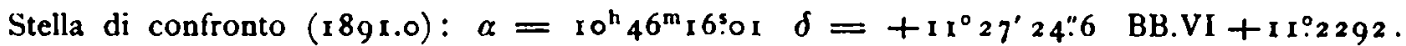

Il moto approssimato in 24 ore mi risultó di $-60^{8}+1 I^{\prime}$.

Roma 189 I marzo 2.

\section{E. Millosevich.}

*) Durch Telegramm bereits am 2. März mitgetheilt und weiterverbreitet. Kr.

\section{Entdeckung eines neuen Planeten (308) auf der Sternwarte in Nizza.}

Telegramm: "Planète Charlois 5 Mars $8^{\mathrm{h}} 46^{\mathrm{m}} .7 \mathrm{t}$. m. Nice AR. app. $=150^{\circ} 21^{\prime} 32^{\prime \prime}$ DP. app. $=70^{\circ} 17^{\prime} 50^{\prime \prime}$; Mouvement diurne: $-\mathrm{I}^{\prime}$ et $-4^{\circ}$. Grandeur treizième. Différente de Vera. Perrotin.e

In halt 2u Nr. 3023. T. E. Espin. Stars with remarkable Spectra. 361. - W. Doberck. Markree Double-Star Observations. 365. - T. E. Espirs. A New Variable Star in Camelopardus. 381, - F. Bidschof. Ephemeride für den Cometen 189011. 381 - F. Palisa. Beob. achtung des Planeten (305), entdeckt von Palisa 1891 Febr. 14. 381. - W. Luther. Beubachtungen des Planeten (306), entdeckt von Charlois 1891 Febr. 16. 381. - Todes-Anzeige. 383. - E. Millosevich. Entdeckung und Beobachtung eines neuen Planeten (307). 383. - Entdeckung eines neuen Planeten (308) auf der Sternwarte in Nizza. $3^{83}$. 